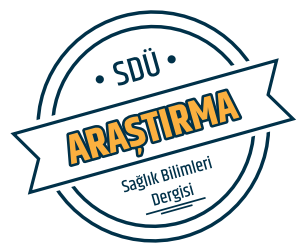

Sdü Sağlık Bilimleri Dergisi / Cilt 10 Sayı 3 / 2019

\title{
Zihinsel Engelli Çocukların Sağlıklı Kardeşlerinin Benlik Saygısı ve Okul Başarısının Belirlenmesi
}

\section{Determination of Self-Respect and School Success of the Healthy Siblings of the Mentally Disabled Children}

\author{
Birgül Tuncay', Sevinç Polat ${ }^{2}$ \\ ${ }^{1}$ Gümüşhane Üniversitesi Kelkit Sağlık Hizmetleri Meslek Yüksekokulu, Çocuk Gelişimi Programı, Gümüşhane, Türkiye. \\ ${ }^{2}$ Yozgat Bozok Üniversitesi Sağlık Bilimleri Fakültesi, Çocuk Sağlığı ve Hast. Hemş. Anabilim Dalı, Yozgat, Türkiye.
}

\section{Özet}

Amaç: $\mathrm{Bu}$ araştırma zihinsel engelli çocukların sağlıklı kardeşlerinin benlik saygısı ve okul başarılarını belirlemek amacıyla yapılmıştır.

Materyal-Metot: Araştırma tanımlayıcı nitelikte bir çalışmadır. Araştırma kapsamına, İç Anadolu'da bir İl merkezinde bulunan, Milli Eğitim Müdürlüğü'ne bağlı özel eğitim veren iki okula kayıtlı zihinsel engelli kardeşi olan, 9-17 yaş arası 91 sağlıklı çocuk alınmıștır. Verilerin toplanmasında Tanıtıcı Bilgi Formu, Coopersmith Benlik Saygısı Envanteri Kısa Formu ve sağlıklı kardeşlerin yılsonu okul başarı puanlarını öğrenmek için e-okul sistemi kullanılmıştır. Verilerin analizinde sayı, yüzdelik dağılım, Mann-Whitney U testi, Kruskall-Wallis test ve Spearman Korelasyon analizleri kullanılmıştır.

Bulgular: Araştırma kapsamına alınan zihinsel engelli çocukların sağlıklı kardeşlerinin \%42,8'inin 12-14 yaş grubunda ve $\% 57,1$ 'inin k1z olduğu, \%42,8'inin ikinci düzey ilköğretim sınıflarına devam ettiği belirlenmiştir. Zihinsel engelli çocukların sağlıklı kardeşlerinin benlik saygısı puan ortalaması 59,2 $\pm 14,9$, \%60,4'ünün yılsonu okul başarı derecesinin “iyi”, \%27,5'nin ise “orta” olduğu belirlenmiştir. Sağlıklı kardeşlerin \%33’ü engelli kardeşinden utandığını, \%15,4'ü engelli kardeşinden dolayı suçluluk hissettiğini, \%48,4'ü ise ailesinin kendisinden daha çok engelli kardeşiyle ilgilendiğini belirtmiştir.

Sonuç: Araştırmada sağlıklı kardeşlerin \%69,2'sinin orta düzeyde, \%27,5'nin ise yüksek düzeyde benlik saygısına sahip olduğu bulunmuştur. Sağlıklı kardeşlerin cinsiyeti, yaşı ve devam ettiği sınıfın benlik saygısı toplam puan ortalamalarını etkilemediği belirlenmiştir ( $p>0,05)$. Araştırmada sağlıklı kardeşlerin benlik saygısı ile okul başarı dereceleri arasında ilişki saptanmamıştır.

Anahtar kelimeler: Zihinsel Engel, Sağlıklı Kardeş, Benlik Saygısı, Okul Başarısı.

\begin{abstract}
Objective: This study was conducted in order to determine the self-respect and school success of the healthy siblings of the trainable mentally disabled children.
\end{abstract}

Material-Method: The healthy siblings of 91 mentally disabled children who are getting private training in a city center in Central Anatolia and who have siblings between the ages of 9 and 17 were included in the study. The data of the study was collected by informative data form and Coopersmith Self- Esteem Inventory Short Form. The school grades of the healthy siblings at the end of the year were obtained from e-school system. Descriptive statistics, Mann-Whitney U test, Kruskall-Wallis and Spearman Correlation analysis were used to evaluate the data.

Results: It was determined that, of the healthy siblings of the mentally disabled children included in the study, $42.8 \%$ were between the ages of $12-14$ and $57.1 \%$ were female, $42.8 \%$ were attending second-level primary school classes. It was found that the self-respect point average of the healthy siblings of the mentally disabled children was $59.2 \pm 14.9$. The school success level of $60.4 \%$ of the healthy siblings at the end of the year was found to be 'good', $27.5 \%$ were 'middle'. $33 \%$ of the healthy siblings were ashamed of their disabled siblings, $15.4 \%$ felt guilty of their disabled siblings, and $48.4 \%$ stated that their family was more interested in their disabled siblings.

Conclusions: In this study, It was found that healthy siblings of the mentally disabled children $69.2 \%$ of them had medium level, $27.5 \%$ of them high level of self-respect. It was determined that the sex, age and class of attendance of the healthy siblings did not affect the self-respect point average of the healthy siblings. In this study, no relationship was established between the self-respect of the healthy siblings and their levels of success at school.

Keywords: Mental Disability, Healthy Sibling, Self-Respect, School Success.
DOI: $10.22312 /$ sdusbed.517323

Müracaat tarihi / Received date: 24.01 .2019

Kabul tarihi / Accepted date: 09.09.2019
Yazışma Adresi / Corresponding: Birgül Tuncay

Gümüşhane Üniversitesi Kelkit Sağlık Hizmetleri Meslek Yüksekokulu 29600

Kelkit / Gümüşhane, Türkiye.

Tel: 04562331053

Fax: 04562331007

E-posta / E-mail: birgul-koc@hotmail.com 


\section{Giriş}

Tüm toplumlarda çocuklar, geleceğin yetişkini olarak özenle yetiştirilen, eğitilen ve eldeki olanaklar en üst düzeyde kullanılarak, tüm gereksinimleri karşılanan değerli bireylerdir. Çocukların her yönüyle sağlıklı bir gelişim seyri içinde büyümesini izlemek aile üyelerinin en önemli isteklerinden biridir (1). Ancak her gün çok sayıda çocuk engelli olarak doğmakta ya da sonradan herhangi bir nedenle engelli olmaktadır. Çocuklarda sık görülen ve engel türleri içerisinde ikinci sırada yer alan zihinsel engellilik; zihinsel işlevlerin yanı sıra kavramsal, sosyal ve pratik uyum becerilerinde sinırlılıklara neden olan bir durumdur. Zihinsel engelli çocuklar; bireysel bakımında, iletişimde, toplumsal yeteneklerinde, sağlığını koruma ve günlük yaşamda karşılaşılan sorunları çözmede çeşitli derecelerde güçlük yaşamaktadırlar $(2,3)$.

Ailedeki bireylerden herhangi birinin hastalık ya da yetersizliği tüm aile bireylerine olumsuz olarak yansımaktadır. Çünkü çocuklarda görülen herhangi bir yetersizlik durumunda ebeveynlerle birlikte ailedeki sağlıklı çocuklar da bu durumdan yoğun olarak etkilenmektedir. Ailede engelli bir çocuğun varlığı durumunda öncelikle ebeveynlerin anne baba rollerinde, özel yaşamlarında, sosyal çevrelerinde, planlarında, iş yaşamlarında, ailenin yapısında, işleyişinde ve mali konularda büyük değişiklikler yaşanmaktadır $(4,5)$. Kardeş ilişkisinin niteliği değişmekte, sağlıklı kardeşlerin duygusal ve psiko-sosyal gelişimi olumsuz etkilemekte ve bu duruma bağlı olarak sağlıklı kardeşlerde gelişim ve kişilik sorunları görülmektedir $(1,6)$.

Kişiliğin temel özelliklerinden biri olan benlik; kişinin kendisine olan bakış açısı ve kendi zihninde, kendisini temsil ediş şekli olarak yorumlanmaktadır. Çocuk doğumundan itibaren annesi, babası, kardeşi ve arkadaşlarından edindiği bilgilere dayanarak benlik kavramını oluşturur. Benlik saygısı, kişinin kendini değerlendirmesi sonucunda ulaştığ1, benlik kavramının onaylamasından doğan beğeni durumunu ifade etmektedir. Çocuğa değer verilmesi, önemsenmesi, kabul ve onay görmesi ve gereksinimlerine duyarlı olunması çocukta yüksek benlik saygısının gelişmesine katkıda bulunur. Ailede zihinsel engelli bir çocuğun varlığı, sağlıklı çocuğun ihtiyaçlarının karşılanma ve desteklemesinde yetersiz kalınmasına bu durum ise benlik saygısının olumsuz yönde etkilenmesine neden olur $(7,8)$.

Eğitim düzeyi doğrudan yaşam kalitesini etkileyen bir göstergedir. Bu nedenle sağlıklı ya da engelli tüm çocukların eğitimlerini başarı ile tamamlamaları beklenmektedir. Çocuğun okul başarısında ailenin çok önemli bir payı bulunmaktadır. Yapılan araștırmalarda; akademik başarısı düşük ve sınıfta kalma riski taşıyan öğrencileri diğer öğrencilerden ayıran en önemli etkenin, anne-baba desteği ve ilgisinden yoksunluk olduğu saptanmıştır (9). Ancak zihinsel engelli çocuğa sahip olan aileler, zamanının büyük bir kısmını engelli çocuğa ayırdıkları için sağlıklı çocuklarına yeteri kadar zaman ayıramamaktadırlar. Bu nedenle anne baba desteği ve ilgisinden yeterince yararlanamayan sağlıklı çocukların okul başarıları olumsuz etkilenmektedir $(9,10)$. Ülkemizde sağlıklı çocukların okul başarılarını inceleyen çeşitli araştırmalar bulunmakla birlikte zihinsel engelli çocukların sağlıklı kardeşlerinin okul başarılarını araştıran herhangi bir çalışmaya rastlanmamıştır (11-13). Oysa sağlıklı kardeşlerin bu konuda yeterli desteklenebilmeleri ve okul başarılarının arttırılması için bu konu ile ilgili kapsamlı çalışmalara ihtiyaç duyulmaktadır.

Zihinsel yetersiz çocuk ve ailesinin bakımı disiplinler arası bir ekip yaklaşımını gerektirmektedir. Hemşire, bu ekipte zihinsel yetersiz çocuk ve ailesini bakımın merkezine alarak diğer ekip üyeleriyle koordinasyonu sağlayabilecek anahtar kişidir. Zihinsel yetersiz çocuk ve ailesine bakım veren hemşirelerin eğitici, danışman, savunucu, karar verici gibi birçok bağımsız rolleri bulunmaktadır. Hemşirenin engelli çocukların tedavi ve rehabilitasyonunun yanı sıra, sağlıklı kardeşlerin içinde bulundukları duruma uyum sağlamaları ve yaşadıkları sorunların çözümüne yönelik uygun eğitim ve danışmanlık hizmetlerini sağlaması ve yürütmesi gerekmektedir $(14,15)$. $\mathrm{Bu}$ araştırmada, zihinsel engelli çocukların sağlıklı kardeşlerinin benlik saygısı ve okul başarısının değerlendirmesi amaçlanmıştır.

\section{Materyal-Metot}

Betimsel bir çalışma olan bu araştırmada tarama modeli kullanılmıştır. Araştırmanın evrenini 2012-2013 eğitim öğretim yılında İç Anadolu'da bir İl merkezinde, Milli Eğitim Müdürlüğü'ne bağlı özel eğitim merkezinde eğitim gören zihinsel engelli çocukların, sağlıklı gelişim gösteren 9-17 yaş arasındaki kardeşleri oluşturmaktadır. Araştırma, sağlıklı çocukların velisi ve kendisi tarafından araştırmaya katılması onaylanan 91 sağlıklı kardeş ile yürütülmüştür.

Araştırmaya Alınma Kriterleri

- Zihinsel engelli kardeşe sahip olan,

- 9 ile 17 yaş aralığında bulunan,

- İlköğretim veya ortaöğretim eğitimine devam eden,

- Herhangi bir zihinsel ve fiziksel engeli ile psikiyatrik rahatsızlığı bulunmayan,

- Çalışmaya katılması ailesi ve kendisi tarafından kabul edilen,

- Algılama ve iletişim sorunu bulunmayan çocuklar araştırma kapsamına alınmıştır.

Verilerin toplanması amaciyla; Tanıtıc1 Bilgi Formu, Coopersmith Benlik Saygısı Ölçeği (CBSÖ) ve sağlıklı çocukların yılsonu okul başarı puanları kullanılmıştır.

Tanıtıcı Bilgi Formunda; zihinsel engelli çocuğa ait özellikler, sağlıklı kardeşe ilişkin sosyodemografik özellikler ve sağlıklı çocuğun zihinsel engelli kardeşle ilişkilerini sorgulayan sorular yer almaktadır.

Coopersmith Benlik Saygısı Envanteri (Coopersmith Selfesteem Inventory); Stanley Coopersmith (1986) tarafindan geliştirildikten sonra, yapılan revize çalışmalarından sonra 3 formu geliştirilmiştir. (Yetişkin Formu, Okul Formu ve Okul Kısa Formu) $\mathrm{Bu}$ araştırmada Coopersmith Benlik Saygısı Envanteri Okul Kısa Formu kullanılmıştır. Okul Kısa Formu yaşları 8-15 arası olan öğrenciler için kullanılmaktadır.

Ölçeğin Türkçe'ye çevirisini ve geçerlik güvenirlik çalışmasını ilk olarak Özoğul (1998) yapmış, daha sonra Coopersmith Benlik Saygısı Envanterinin geçerlik güvenirlik çalışması Gürçay (1989) tarafından yapılmıştır (16). Ancak 
yukarda bahsedilen her iki araştırmacı da ölçeğin geçerlik ve güvenirlik çalışmalarını ilköğretim öğrencilerine uyguladığı ve lise öğrencileriyle uygulama yapılarak geçerlik güvenirlik çalışmalarının yapılması gerektiği düşüncesi ile Pişkin (1997), 151 İngiliz ve 315 Türk öğrenciye uygulayarak ölçeğin geçerlik güvenirlik çalışmalarını yapmış ve ölçeğin kısa formu için KR-21 katsayısını 0,83 olarak hesaplamıştır. Ölçek, "benim gibi" ya da "benim gibi değil" biçiminde işaretlenebilen 25 maddeden oluşmaktadır. $\mathrm{Bu}$ maddelerde kişinin hayata bakış açısı, aile ilişkileri, sosyal ilişkileri ve dayanma gücü ile ilgili ifadeler bulunmaktadır. Alınan puanlar 0 ile 100 arasında değişmektedir.

Öğrenci başarısının değerlendirilmesi: Sağlıklı kardeşlerin okul başarılarının tespiti için 2012-2013 eğitim öğretim yılının ilk yarısının değerlendirilmesi planlanmıştır. Sağlıklı çocukların okul başarı puanları, çocuklar ve aileleriyle birlikte şifreleri kullanılarak Milli Eğitim Bakanlığı'nın e-okul sisteminden alınmıştır.

Araştırmaya alınan sağlıklı çocuklara veri toplama formlarının nasıl doldurulacağına dair açıklama yapılarak, formlar dağıtılmıştır. Araştırmacı ve rehber öğretmen gözetiminde sağlıklı kardeşlerin veri toplama formlarını doldurmaları sağlanmıştır.

Araştırmaya başlamadan önce Erciyes Üniversitesi Sağlık Bilimleri Fakültesi Akademik Kurulu ile Erciyes Üniversitesi Klinik Araştırmaları Etik Kurulu'ndan (07.08.2012 tarih 2012/478 no'lu), ve araştırmanın yapılacağı okullarda ilgili İl Milli Eğitim Müdürlüğü'nden (23.07.2012 tarih 9390 no’lu) resmi izin alınmıştır. Ayrıca araştırmaya katılan sağlıklı çocuklara ve ailelerine, araştırma hakkında bilgi verilerek yazılı ve sözlü onamları alınmıştır.

Araştırmadan elde edilen verilerin tanımlayıcı istatistikleri için sayı, yüzde, ortalama, standart sapma kullanılmıştır. Kullanılan verilerin öncelikle normal dağılıma uygunluk testi (Kolmogrov-smirnov testi) yapılmıştır. Verilerin normal dağılıma uymadıkları tespit edildikten sonra verilerin değerlendirilmesinde; Mann-Whitney U testi ve KruskallWallis varyans analizi kullanılmıştır. Araştırmada sağlıklı kardeşlerin Coopersmith Benlik Saygısı Ölçeği'nden aldıkları puan ile yılsonu okul başarı puanları arasındaki ilişkiyi belirlemek için Spearman Korelasyon analizi yapılmıştır. Grupların karşılaştırılmasında sonuçların istatistiksel anlamlılığ1 $\mathrm{p}<0,05$ düzeyinde değerlendirilmiştir.

\section{Bulgular}

Zihinsel engelli çocukların sağlıklı kardeşlerinin; \%57,1'inin kız, \%42,8'inin 12-14 yaş grubunda ve \%51,6'sının engelli kardeșiyle birlikte iki kardeșinin olduğu belirlenmiştir. Sağlıklı kardeşlerin \%42,8'inin ikinci düzey ilköğretim sınıflarına devam ettiği saptanmıştır (Tablo 1).

Araştırmaya katılan sağlıklı kardeşlerin zihinsel engelli kardeşleri hakkındaki görüşleri Tablo 2'de verilmiştir. Sağlıklı kardeşlerin \%33'ünün engelli kardeşinden utandığını, \%69,2'sinin kardeşinin engelinden dolayı suçluluk hissetmediğini, \%51,6'sının zaman zaman kardeşinin engelinden dolayı sosyal çevreyle uyum sorunu yaşadığını, \% 48,4'ünün ailesinin daha çok engelli kardeşi ile ilgilendiğini düşündüğü belirlenmiştir (Tablo 2).
Tablo 1. Sağlıklı kardeşlerin tanıtıcı özellikleri (n=91)

\begin{tabular}{lcc}
\hline Tanıtıcı özellikler & $\mathbf{n}$ & $\mathbf{\%}$ \\
\hline Yaş & 36 & 39,6 \\
9-11 yaş & 39 & 42,8 \\
12-14 yaş & 16 & 17,6 \\
15-17 yaş & & \\
\hline Cinsiyet & 52 & 57,1 \\
Kız & 39 & 42,9 \\
Erkek & & \\
\hline Doğum sırası & 19 & 20,9 \\
İlk çocuk & 25 & 27,5 \\
İkinci çocuk & 33 & 36,3 \\
Üçüncü çocuk & 14 & 15,3 \\
Dördüncü çocuk ve sonras1 & & \\
\hline Kardeş sayıs1 & 14 & 15,4 \\
1 kardeş & 47 & 51,6 \\
2 kardeş & 25 & 27,5 \\
3 kardeş & 5 & 5,5 \\
4 kardeş & & \\
\hline Devam ettiği sınıf & 28 & 30,8 \\
İlköğretim 1. Düzey(3-5.sınıf) & 39 & 26,4 \\
İlköğretim 2. Düzey (6-8.sinıf) & 24 & \\
Lise (9-11.sınıf) & & \\
\hline
\end{tabular}

Tablo 2. Sağlıklı çocukların zihinsel engelli kardeşleri hakkındaki görüşleri ( $\mathrm{n}=91)$

\begin{tabular}{lcc}
\hline Görüşler & n & \% \\
\hline Kardeşinin engelli olmasından utanma durumu & & \\
Utanıyorum & 30 & 33,0 \\
Utanmıyorum & 38 & 41,8 \\
Bazen utanıyorum & 23 & 25,2 \\
\hline Kardeşinin engelli olmasından dolayı suçluluk & & \\
hissetme durumu & & \\
Suçluluk hissediyorum & 14 & 15,4 \\
Suçluluk hissetmiyorum & 63 & 69,2 \\
Bazen suçluluk hissediyorum & 14 & 15,4 \\
\hline Sosyal çevre ile uyum sorunu yaşama & & \\
Uyum sorunu yaşıyorum & 22 & 24,2 \\
Uyum sorunu yaşamıyorum & 22 & 24,2 \\
Bazen uyum sorunu yaşıyorum & 47 & 51,6 \\
\hline Ailesinin engelli kardeşiyle daha fazla ilgilendiğini & & \\
düşünme durumu & & \\
Düşünüyorum & 44 & 48,4 \\
Düşünmüyorum & 22 & 24,1 \\
Bazen düşünüyorum & 25 & 27,5 \\
\hline & &
\end{tabular}


Tablo 3. Sağlıklı kardeşlerin CBSÖ göre aldığı puanlar ve okul başarı puanları $(\mathrm{n}=91)$

\begin{tabular}{lcc}
\hline & $\mathbf{n}$ & $\mathbf{\%}$ \\
\hline Benlik saygısı puanı & & \\
10-30 puan (Düşük) & 3 & 3,3 \\
31-70 puan (Orta) & 63 & 69,2 \\
$71-100$ puan (Yüksek) & 25 & 27,5 \\
$(\mathrm{X} \pm \mathrm{SD}=59.2 \pm 14.9)$ (Min-Max=28-84) & & \\
\hline Okul başarı puanı & & \\
45-54 puan (Geçer) & 4 & 4,4 \\
$55-69$ puan (Orta) & 25 & 27,5 \\
$70-84$ puan (İyi) & 55 & 60,4 \\
$85-100$ puan ( Pekiyi) & 7 & 7,7 \\
$(\mathrm{X} \pm \mathrm{SD}=72.2 \pm 8.2)($ Min-Max=50-86) & \multicolumn{3}{c}{} \\
\hline
\end{tabular}

Tablo 4. Sağlıklı kardeşlerin tanıtıcı özelliklerine göre CBSÖ ve yılsonu başarı puan ortalamaları

\begin{tabular}{lcccc}
\hline Tanıtıcı Özellikler & n & $\begin{array}{c}\text { Coopersmith } \\
\text { Benlik Saygısı } \\
\text { Ölçeği }\end{array}$ & Test & p \\
\hline Cinsiyet & 52 & $59,15 \pm 14,95$ & & \\
Kız & 39 & $59,28 \pm 15,15$ & $\mathrm{U}=1012,500$ & 0,990 \\
Erkek & & & & \\
\hline Yaş & 36 & $59,33 \pm 14,35$ & & \\
9-11 yaş & 39 & $60,51 \pm 13,67$ & $\mathrm{KW}=1,065$ & 0,587 \\
12-14 yaş & 16 & $55,75 \pm 19,23$ & & \\
15-17 yaş & & & & \\
\hline
\end{tabular}

\section{Devam ettiği sınıf}

İlköğretim

1.Düzey(1-5sınıf) $28 \quad 58,14 \pm 14,82$

İlköğretim 2.

Düzey (6-8 sinıf)

$3959,69 \pm 13,18$

$\mathrm{KW}=0,207 \quad 0,902$

Lise (9-12. Sinıf) $24 \quad 59.66 \pm 18.11$

\section{Doğum Sırası}

\begin{tabular}{lrrrr} 
Büyük kardeş & 34 & $60,82 \pm 15,81$ & & \\
Küçük kardeş & 57 & $58,24 \pm 14,48$ & & \\
\hline U: Mann-Whitney U KW: Kruska-Wallis & & 0,397 \\
\hline
\end{tabular}

U: Mann-Whitney U KW: Kruskal-Wallis

Tablo 5. Sağlıklı çocukların benlik saygısı düzeyleri ile okul başarı dereceleri arasındaki ilişki

\begin{tabular}{lcc}
\hline & \multicolumn{2}{c}{ Okul Başarı Derecesi } \\
& $\mathrm{r}_{\mathrm{s}}$ & $\mathrm{p}$ \\
\cline { 2 - 3 } Benlik Sayg1s1 Düzeyi & 0,023 & 0,832 \\
\hline $\mathrm{r}_{\mathrm{s}}=$ Spearman korelasyon & &
\end{tabular}

Araştırma kapsamına alınan zihinsel engelli çocukların sağlıklı kardeşlerinin benlik saygısı puan ortalaması 59,2 $\pm 14,9$ olup, puan aralığ $128-84$ 'dür. Sağlıklı kardeşlerin \%69,2'sinin orta düzeyde, \%27,5'nin yüksek düzeyde benlik saygısına sahip olduğu ve \%60,4'ünün yılsonu okul başarı puanının 70-84 puan aralığında olduğu belirlenmiştir (Tablo 3).
Sağlıklı kız kardeşlerin CBSÖ toplam puan ortalamaları $59,15 \pm 14,95$, erkek kardeşlerin CBSÖ puan ortalamaları $59,28 \pm 15,15$ olarak belirlenmiş ve aralarında istatistiksel olarak anlamlı fark olmadığı saptanmıştır $(\mathrm{p}>0,05)$. 12-14 yaş grubunda olan sağlıklı kardeşlerin CBSÖ puan ortalamalarının $(60,51 \pm 13,67)$ diğer gruplara göre yüksek olduğu bulunmuş ancak gruplar arasında istatistiksel olarak anlamlı fark saptanmamıștır $(p>0,05)$. Zihinsel engelli çocuktan büyük olan sağlıklı kardeşlerin benlik saygısı puan ortalamalarının küçük olanlara göre daha yüksek olduğu belirlenmiş ancak aralarında istatistiksel olarak anlamlı fark bulunmamıştır ( $>0,05)$ (Tablo 4).

Yapılan korelasyon analizi sonucu; zihinsel engelli çocukların sağlıklı kardeşlerinin benlik saygısı düzeyleri ile okul başarı dereceleri arasında ilişki olmadığı bulunmuştur $(p>0,05)$ (Tablo 5).

\section{Tartışma}

$\mathrm{Bu}$ araştırmada, zihinsel engelli çocukların sağlıklı kardeşlerinin çoğunun orta düzeyde benlik saygısına sahip olduğu saptanmıştır. Bulgularımızın aksine Van Riper'in Down Sendrom'lu çocukların sağlıklı kardeşleri ile ilgili yaptığı çalışmada; engelli çocukların kardeşlerinin benlik saygısının daha yükssek olduğu belirlenmiştir (17). Saban'ın zihinsel engelli kardeşe sahip olan ve olmayan çocukların benlik saygısı ve kaygı durumlarını incelediği çalışmada da; zihinsel engelli kardeşe sahip olan çocukların benlik saygısının daha yüksek olduğu bulunmuştur (18).

Araştırmada sağlıklı kardeşlerin cinsiyeti, yaşı, çocuk sırası ve devam ettiği sınıfın benlik saygısı toplam puan ortalamalarını etkilemediği belirlenmiştir. Dyson'ın gelişimsel bozukluğu olan çocukların okul çağındaki kardeşlerinin psikososyal fonksiyonlarını araştırdığı çalışmada da, engelli kardeşe sahip olma durumu ile benlik saygısı arasında anlamlı bir farklılık olmadığı bulunmuştur (19). Bulgularımızın aksine Erbil ve ark. ergenlerin benlik saygısına anne-babanın tutum ve davranışlarının etkisini belirlemek amacıyla yaptıkları bir çalışmada; kardeş sayısı, anne eğitim düzeyi, anne-baba tutum ve davranışları ile ergenlerin benlik saygısı puanları arasında istatistiksel olarak anlamlı fark bulunduğu belirlenmiştir (20). Çocukların benlik kavramlarını çeşitli değişkenler açısından değerlendirildiği bir başka çalışmada; benlik saygısı düzeyleri düşük olan çocukların kendilerine sunulan yeni aktivitelere girmek istemediği, hata yapmaktan aşırı korktuğu, kendilerine daha az güven duydukları ve kendilerinden istenenleri başaramayacakları duygusu ile başarısız oldukları belirlenmiştir (21). Bu araştırmada sağlıklı kardeşlerin yaşı, cinsiyeti, çocuk sırası ve devam ettiği sınıf ile yılsonu okul başarı puanları arasında istatistiksel olarak fark olmadığı saptanmıştır. Bu durumun sağlıklı kardeşlerin çoğunun orta düzeyde benlik saygısına sahip olmasının, yılsonu okul başarı notuna olumlu yansımasının bir sonucu olduğu söylenebilir. Engelli çocuğun engelinin diğer sağlıklı kardeşler üzerinde; ebeveyn ilgisinden yoksun kalma, kardeşe bakma sorumluluğunda artış, engelli kardeşin sınırlılıklarının yarattığ 1 baskıya maruz kalma, toplum tarafından etiketlenme, sağlıklı kardeş ile etkileşimin azalması ve ailedeki rollerin değişmesi gibi olumsuzluklara neden olmaktadır (22). 
Araştırmada zihinsel engelli çocuktan küçük olan sağlıklı kardeşlerin yılsonu okul başarı puan ortalamalarının, büyük olanlara göre daha yüksek olduğu saptanmıştır. Bu sonuçta büyük kardeşlerin engelli kardeşine bakma konusunda küçük kardeşlere göre daha fazla sorumluluk almaları, okul ve ders çalışmak için ise yeterli zaman ayıramamaları ve kardeş ilişkilerinin olumsuz yansımasının etkili olduğu söylenebilir. Araştırma kapsamına alınan zihinsel engelli çocukların sağlıklı kardeşlerinin benlik saygısı puan ortalamaları ile yılsonu okul başarı puan ortalamaları arasında ilişki saptanmamıştır. $\mathrm{Bu}$ durumun örneklem grubunun farklı olmasına aynı zamanda çocukların ailede ve okuldaki destek kaynaklarına bağlı olduğu düşünülmektedir.

\section{Sonuç}

Araştırmada normal gelişim gösteren, sağlıklı kardeşlerin benlik saygısının ve okul başarısının istendik düzeyde olmadığı belirlenmiştir. Zihinsel engelli çocukların sağlıklı kardeşlerinin içinde bulundukları duruma uyum sağlamaları ve yaşadıkları sorunların çözümüne yönelik uygun eğitim ve danışmanlık hizmetlerinin okulların rehberlik birimi ve sağlık çalışanları özellikle hemşireler tarafından sağlanması ve yürütülmesi gerektiği düşünülmektedir.

Bu çalışma Ocak 2014 yılında Erciyes Üniversitesi Sağlık Bilimleri Enstitüsü Hemşirelik yüksek lisans tezi olarak kabul edilmiş ve European Academy of Paediatric Socities Kongresi 17-21 Ekim 2014 tarihinde Barselona / İspanya'da poster bildiri olarak sunulmuştur.

\section{Kaynaklar}

1. Er M. Çocuk, hastalık, anne-babalar ve kardeşler. Çocuk Sağlığı ve Hastalıkları Dergisi 2006; 49: 155-168.

2. Eripek S, editör. Zihinsel Yetersizliği Olan Çocuklar. 1. Baskı. Ankara, Maya Akademi, 2009; 51-81.

3. Sucuoğlu B, editör. Zihin Engelliler ve Eğitimleri. 2. Bask1. Ankara, Kök Yayıncılık, 2009; 48-84.

4. Baykoç Dönmez N,Bayhan P, Artan İ. Engelli çocuğa sahip ailelerin beklentileri ve endişe duydukları konuların incelenmesi. Sosyal Hizmetler Dergisi 2000; 1: 16-23.

5. Aylaz R, Yilmaz U, Polat S. Effect of difficulties experienced by parents of autistic children on their sexual life: a qualitative study. Journal Sexuality and Disability 2012; 30: 395-406.

6. Riggio H. R. Measuring attitudes toward adult sibling relationships: the life span sibling relationship scale, Journal of Socialand Personal Relationships 2000; 17: 707-728.

7. Cüceloğlu D, editör. İnsan ve Davranışı Psikolojinin Temel
Kavramları. İstanbul, Remzi Kitabevi, 1994; 24.

8. Yavuzer H, editör. Ana-Baba ve Çocuk. 12. Basım. İstanbul, Remzi Kitabevi, 1999; 10-32.

9. Çelenk S. Okul başarısının ön koşulu: okul aile dayanışması. İlköğretim-Online 2003;2 (2): 28-34.

10. Malkoç G. Aile Eğitimi ve Eğitimde Nitelik Geliştirme, Eğitimde Arayışlar I.Sempozyumu. İstanbul, Kültür Koleji Yayınlar1, 1993; 10-20.

11. Keskin G, Sezgin B. Bir grup ergende okul başarısına etki eden etmenlerin belirlenmesi. Firat Sağlık Hizmetleri Dergisi 2009; 4: 3-18.

12. Bilgin A, Kartal H. İşitme engelli ve engelli olmayan ilköğretim öğrencilerinin benlik kavramları ve akademik başarıları arasındaki ilişkinin incelenmesi. Uludağ Üniversitesi Eğitim Fakültesi Dergisi 2002; 15: 43-52.

13. Atasoy S. Engelli (otistik) kardeşe sahip olan bireylerin kardeş ilişkilerinin incelenmesi [Uzmanlık Tezi]. İzmir, Ege Üniversitesi, 2002; 4-10.

14. Çavuşoğlu H, editör. Çocuk Sağlığı Hemşireliği. Cilt 1. Ankara, Sistem Ofset Basımevi, 2011; 51.

15. Hockenberry M, Wilson D, editors. Wong's Essentials of Pediatric Nursing, 9th ed. Missouri, Mosby, 2009; 2-33.

16. Pişkin M. Türk ve İngiliz Lise Öğrencilerinin Benlik Saygısı Yönünden Karşılaştırılması. III. Ulusal Psikolojik Danışma ve Rehberlik Kongresi Bilimsel Çalışmaları Kongre Kitab1 1997. Adana: Ç.Ü. Eğitim Fakültesi Rehberlik ve Psikolojik Danışma Anabilim Dalı ve Psikolojik Danışma ve Rehberlik Derneği Yayını.

17. Van Riper M. Family variables associated with well-being in siblings of children with DownSyndrome. J Fam Nurs 2000; 6: 267-286.

18. Saban F, Arıkan D. The self- esteem and anxiety of children with and without mentally retarded siblings. Journal of Research In Medical Sciences 2013; 18: 961-969.

19. Dyson LL. The psychosocial functioning of school age children who have siblings developmental disabilities: change andstabilityover time. J Appl Dev Psychol 1999; 20: 253-271. 20. Erbil N, Divan Z, Önder P. Ergenlerin benlik saygısına ailelerinin tutum ve davranışlarının etkisi. Aile ve Toplum Dergisi 2006; 3(10): 7-15.

21. Öztürk S. Anne-babası boşanmış 9-13 yaşlarındaki çocuklar ile aynı yaş grubundaki anne-babası boşanmamış çocukların benlik saygısı ve kaygı düzeyleri ilişkisi [Yüksek Lisans Tezi]. İzmir, Dokuz Eylül Üniversitesi, 2006; 6-37. 22. Coruthamel CS. Siblings of handicapped children: a group support program. Early Child and Care 1998; 37: 119-131. 